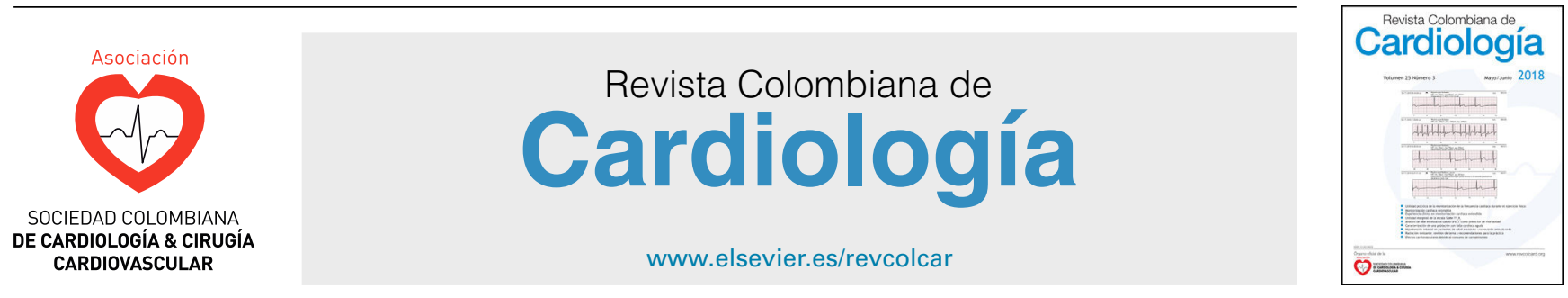

ARTÍCULO ESPECIAL

\title{
El ambiente, los desplazamientos y el riesgo cardiovascular en la pandemia por COVID-19
}

\section{Fernando Lizcano* y Felipe Arroyave}

\author{
Centro de Investigación Biomédica, Universidad de La Sabana, Chía, Colombia
}

Recibido el 5 de mayo de 2020; aceptado el 14 de mayo de 2020

Disponible en Internet el 25 de mayo de 2020

\section{PALABRAS CLAVE \\ COVID-19; \\ Ambiente; \\ Desplazamientos \\ poblacionales; \\ Riesgo cardiovascular}

\section{KEYWORDS}

COVID-19;

Environment;

Population

movement;

Cardiovascular risk

\begin{abstract}
Resumen La pandemia por COVID-19 ha desencadenado un impacto tremendo en la humanidad debido a las implicaciones culturales, económicas y sociales que este tipo de infecciones ha ocasionado. Quizá preguntas iniciales, mirando en retrospectiva corta, acerca de los hechos que comenzaron esta infección, darían una luz para prevenir eventos de esta índole en el futuro. ¿Cuáles fueron las circunstancias que desencadenaron la pandemia?, ¿fue una serie de transmisiones zoonóticas que produjeron la infección en los humanos?, ¿ha tenido algo que ver el ambiente? El desafío de las grandes potencias para mantener la hegemonía, dará curso a una plétora de investigaciones acerca de la biología del virus, las variables epidemiológicas y las enfermedades crónicas de riesgo cardiovascular. En este manuscrito se analizan algunos de estos cuestionamientos.

(C) 2020 Sociedad Colombiana de Cardiología y Cirugía Cardiovascular. Publicado por Elsevier España, S.L.U. Este es un artículo Open Access bajo la licencia CC BY-NC-ND (http:// creativecommons.org/licenses/by-nc-nd/4.0/).
\end{abstract}

The environment, movements, and cardiovascular risk in the COVID-19 pandemic

Abstract The COVID-19 pandemic has had a tremendous impact on humanity due to the cultural, financial, and social implications caused by this type of infection. Perhaps some initial questions, looking at the short-term retrospective, about the facts that started this infection, could shed some light on preventing events of this kind in the future. What were the circumstances that triggered the pandemic? Was it a series of zoonotic transmissions that produced the infection in humans? Is it something to do with the environment? The challenge of the major powers to maintain dominance, will give rise to a plethora of studies on the biology of the virus, the epidemiological variables, and the chronic diseases of cardiovascular risk. Some of these questions are analysed in this article.

(C) 2020 Sociedad Colombiana de Cardiología y Cirugía Cardiovascular. Published by Elsevier España, S.L.U. This is an open access article under the CC BY-NC-ND license (http:// creativecommons.org/licenses/by-nc-nd/4.0/).

* Autor para correspondencia.

Correo electrónico: fernando.lizcano@unisabana.edu.co (F. Lizcano). 


\section{El virus SARS-CoV-2}

El SARS-CoV-2, o coronavirus 2 del síndrome respiratorio agudo grave, es el séptimo coronavirus que se sabe que infecta a los humanos; SARS-CoV, MERS-CoV y SARS-CoV-2 pueden causar una enfermedad grave, mientras que HKU1, NL63, OC43 y 229E están asociados con síntomas leves ${ }^{1}$.

El tamaño de los viriones de SARS-CoV-2 es de 50 a $200 \mathrm{~nm}$ de diámetro, y su genoma está compuesto de ARN monocatenario en sentido positivo. La secuencia de ARN es de unos 30.000 nucleótidos de longitud ${ }^{2}$. Destaca en su estructura la presencia de unas proteínas en la superficie, que se designan como $S$ (spike), que le dan una característica morfológica que corresponde a estos virus. Sobre la base estructural del SARS-CoV-2 se puede inferir la presencia de una estructura similar a la de los coronavirus observados en algunos mamíferos, como los murciélagos y los pangolines ${ }^{3}$. No obstante, en la proteína $S$ se destacan diferencias significativas en la conformación de la proteína que le permite una unión con mayor afinidad a los receptores de la enzima convertidora de angiotensina 2 (ACE2) ${ }^{4}$.

El dominio de unión al receptor (RBD) en la proteína $S$ es la parte más variable del genoma del coronavirus. Seis aminoácidos de RBD han demostrado ser críticos para la unión a los receptores ACE2 y para determinar el rango de unión de virus similares al SARS-CoV-2. Cinco de estos seis residuos difieren entre SARS-CoV-2 y SARS-CoV. Con base en estudios estructurales y experimentos bioquímicos, el SARSCoV-2 parece tener un RBD que se une con alta afinidad a los ACE2 de humanos, hurones, gatos y otras especies ${ }^{5}$. Adicionalmente, entre las subunidades $S 1$ y $S 2$ de la proteína $S$ existe un sitio de escisión con características polibásicas, cuya función no es reconocida en su totalidad, pero que puede tener una vinculación con la capacidad de introducirse a las células y sirve de blanco para la ruptura con proteasas $^{6,7}$. En este punto surge la primera pregunta: ¿cómo fue el origen del COVID-19 y cómo se desarrolló esta alta afinidad hacia los receptores ACE2 humanos? Es posible que la manipulación de los virus en cultivos celulares de mamíferos o de células humanas haya perfeccionado esta capacidad. Dentro de poco tiempo, estudios genéticos y estructurales podrán reconocer si esta posibilidad es real. Otra posibilidad es que la selección natural en un huésped animal en el mercado de Wuhan haya estado incubándose durante un período invariable de tiempo, antes de la transferencia zoonótica, $y$, por último, la selección natural en humanos después de la transferencia, con lo que la adquisición de la mutación fue generándose en los humanos en un tiempo indeterminado hasta las manifestaciones clínicas al final de $2019^{8}$.

\section{Los grandes desplazamientos que ayudaron a la pandemia}

En el inicio de la pandemia de COVID-19 se observó gran traslado de la población por eventos masivos tanto en China como en Italia, hechos que probablamente influyeron en las condiciones ambientales y la propagación del virus. Por ejemplo, la epidemia en China surgió en el período en que los desplazamientos por circunstancias culturales alcanzaba una tasa alta. El nuevo año lunar en China (Chunyun) tiene la tasa de migración más grande del planeta y es justo en esa fecha cuando la población se dirige hacia sus hogares de origen para reunirse con sus familiares a celebrar la festividad $^{9}$. Algunos consideran que el primer período de la epidemia en China fue previo al día 10 de enero de 2020, la primera fecha de Chunyun, cuando aún no se conocía el peligro de la infección, y no se impusieron intervenciones específicas para el COVID-19. El segundo período fue posterior, dentro del Chunyun, del 10 al 22 de enero de 2020, cuando ocurrió un movimiento masivo de población y se esperaba que acelerara la propagación del COVID-19. Tampoco se impuso ninguna intervención fuerte durante este período del Chunyun. El 20 de enero se realizó el primer anuncio de transmisión e infecciones de humanos a humanos en trabajadores de la salud. Durante este período, los hospitales comenzaron a abarrotarse de pacientes con fiebre o síntomas respiratorios y se observó que el sistema estaba a punto de colapsar ${ }^{10}$.

Pero ¿Qué paso en Italia, España, Francia entre otros países afectados más drásticamente en Europa, o en Estados Unidos en la costa Este? Es posible que el factor común que determinó esta circunstancia coexistiese con un relajamiento en los procesos de protección, ignorancia acerca de las enfermedades transmisibles y mala atención a la primera línea de defensa para prevenir la expansión de la infección. El desarrollo epidémico a finales de febrero ya era bastante similar al visto anteriormente con el SARS y el MERS. En estas dos epidemias anteriores, el punto focal primario fue suprimido y el virus fue detenido ubicando correctamente la primera línea de defensa. Se identificaron los infectados rastreando sus contactos y aislándolos a todos. Por este motivo, se consideraba que en el caso de COVID-19, a fines de febrero de 2020 sería suprimido con éxito poniendo atención al punto focal primario: Wuhan ${ }^{11}$. Adicionalmente, el 28 de febrero se publicaron las primeras estimaciones, que indicaron que se trataba de una enfermedad con una tasa de mortalidad significativamente más baja que la del SARS y el MERS ${ }^{12,13}$. En ese momento era razonable esperar que la epidemia pudiera detenerse pronto. Como resultado, la Organización Mundial de la Salud retrasó la declaración de una pandemia hasta el 11 de marzo ${ }^{14}$.

Históricamente, el desarrollo de algunas de las grandes pandemias en Europa ha comenzado en la península Itálica y en gran medida provenientes de Mongolia o de China. Quizá la más relevante y que causó más muertes fue la peste bubónica, que terminó con un tercio de la población de Europa. De hecho, durante dicha pandemia los puertos de Messina, Palermo, Génova y Venecia, fueron los puntos de penetración de la Yersinia pestis en las fases iniciales de la epidemia ${ }^{15}$, debido, en parte, al gran intercambio comercial en aquellos tiempos de textiles como la seda. En el caso del COVID-19 es posible que los turistas chinos de Wuhan estuvieran visitando el norte de Italia en enero y febrero de 2020 con un propósito similar. Muchos de estos comerciantes chinos, asintomáticos, ingresaron a Italia incluso pasando por los controles de los aeropuertos. Es por esto que algunos plantearon la hipótesis que el fenómeno de la inmigración masiva de trabajadores chinos al norte de Italia haya contribuido a la introducción y propagación temprana del virus ${ }^{16}$. Decenas de miles de inmigrantes chinos trabajan en la industria textil italiana, produciendo artículos de moda, bolsos de cuero y zapatos con la marca "Made in Italy". Trabajaron en condiciones higiénicas pobres y hacinados, lo que 

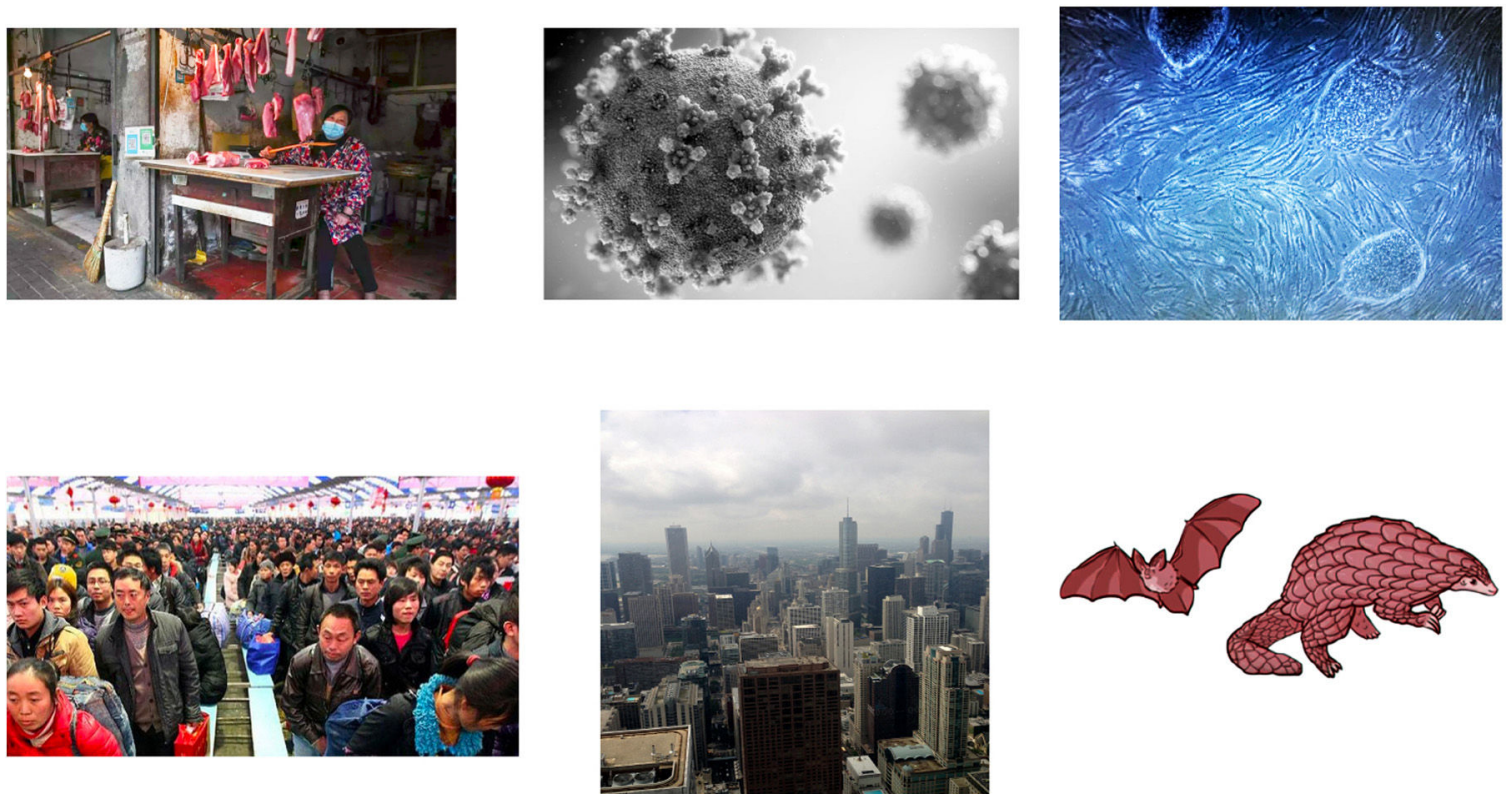

Figura 1 Representación gráfica de las diferentes circunstancias que pudieron dar origen a la infección por COVID-19. En un ambiente con alto contenido de partículas de contaminación, el virus pudo surgir desde un laboratorio, luego de muchos "pasajes" en diferentes líneas celulares, por contaminación zoonótica desde algunos mamíferos, como el pangolín o el murciélago, o luego de la transmisión entre humanos en sitios con alta conglomeración. En las grandes ciudades, el esparcimiento de las políticas públicas y debido a una equivocación al establecer las líneas primarias de defensa, es posible que incrementaran la transmisibilidad de la infección.

facilitaría la propagación. Bajo esta perspectiva, sea a través de turistas chinos, trabajadores textiles o por alguna otra ruta, el nuevo coronavirus desencadenó una epidemia a espaldas de la "primera línea de defensa" italiana que no fue reconocida durante las primeras semanas ${ }^{11}$.

En la época en que se extendió el contagio, las personas infectadas del norte de Italia pasaban los fines de semana en estaciones de esquí del centro de Europa, por lo que podía suponerse que, durante esta época, la condición del frío ayudó a que se propagara el COVID-19 en Europa. De esta manera, muchas personas infectadas surgieron detrás de las líneas de defensa en España, Francia, Suiza, Bélgica, Austria y Dinamarca ${ }^{17}$. Por supuesto en este momento la medida práctica era el cierre de los vuelos procedentes de China. Debido a esto, sus primeras líneas de defensa epidemiológica se centraron en el transporte aéreo desde Asia y no en los propios "'llegados" de las estaciones de esquí, donde, de hecho, nadie esperaría que fuera un gran número de chinos de la zona de Wuhan ${ }^{18}$ (fig. 1).

En el otro lado del Atlántico, los acontencimiento se complicaban por el esparcimiento, en sus dos significados, de las políticas de Estado y en las aglomeradas ciudades del Este de Estados Unidos. Estas poblaciones se consideraban inmunes a cualquier tipo de "gripa" proviniese de donde fuese, pues Boston y Nueva York habían pasado por eventos terroristas de los cuales emergieron sin dificultad. No obstante, en vista de los acontencimiento transcurridos, algunos se han cuestionado por qué Nueva York ha sido tan golpeada por la pandemia. Los expertos en salud pública dicen que una combinación de factores ha contribuido a la propagación desmedida del virus en Nueva York, incluida una respuesta federal políticamente anquilosada y pesada, la gran densidad urbana, las disparidades raciales y económicas, y el papel de la ciudad como centro de comercio y transporte global $^{19}$.

\section{El papel del ambiente en la pandemia}

Las infecciones respiratorias virales se propagan por contacto directo, como tocar a una persona infectada o mediante las superficies y fómites con los que la persona ha estado en contacto, o en las cuales las gotas grandes que contienen virus expiradas por la persona han caído y allí el virus puede permanecer estable durante días. Por lo tanto, lavarse las manos con frecuencia y mantener una distancia de al menos un metro (longitud del brazo) se consideran las principales precauciones contra la infección. Una ruta de transmisión que solo se menciona tangencialmente, o que no se menciona en absoluto, al inicio de la pandemia, es el transporte de partículas cargadas de virus en el aire ${ }^{20}$. Inmediatamente después de que se expiran las gotas, el contenido líquido comienza a evaporarse y algunas gotas se vuelven tan pequeñas que el transporte por corriente de aire las afecta más que la gravitación. Estas pequeñas gotas son libres de viajar en el aire y transportar su contenido viral por decenas de metros desde donde se originaron ${ }^{21}$.

En general, las autoridades de salud pública han quitado importancia a la transmisión de coronavirus por el aire, posiblemente debido a que es difícil detectar directamente los virus que viajan en el aire. El 16 de marzo una declaración lanzada por la Sociedad Italiana de Medicina Ambiental (SIMA) planteó la hipótesis de un posible vínculo entre el impacto dramático del brote de COVID-19 en el norte de Italia y las altas concentraciones de partículas de polución (PM10 y PM2.5 ?m) que caracterizan esta área ${ }^{22}$. 


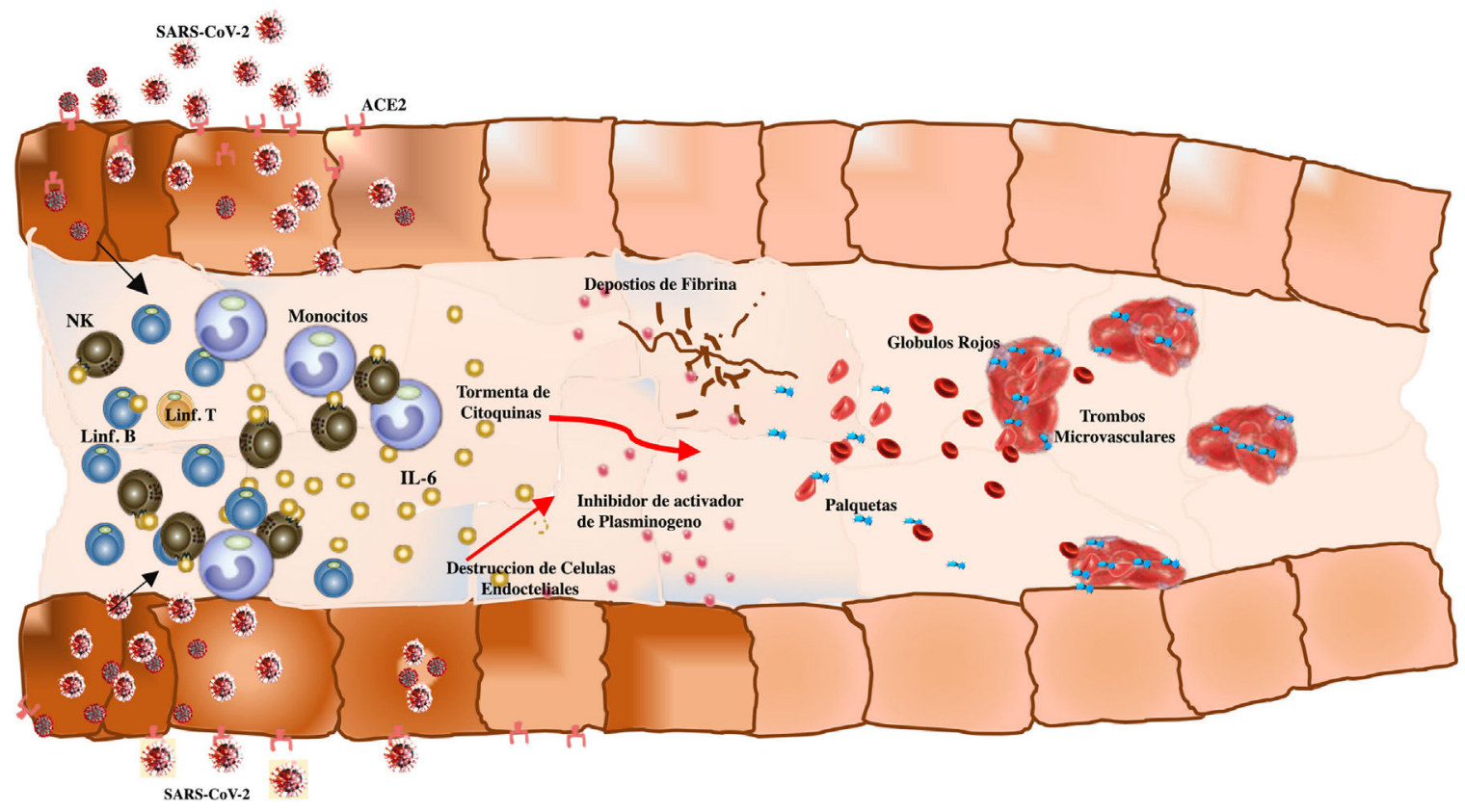

Figura 2 Modelo gráfico de las consecuencias de la infección de COVID-19. El virus SARS-CoV-2 se une a los receptores ACE2; en los individuos predispuestos desencadena una tormenta de citoquinas por la elevada secreción de IL-6 y otras citoquinas. Los niveles de fibrinógeno aumentan y se ocasiona así un estado protrombótico que conlleva lesiones isquémicas en tejido cardiaco, pulmonar y renal.

Posteriormente, una encuesta realizada en los Estados Unidos por la Escuela de Salud Pública Chan de Harvard sugirió una fuerte asociación entre los aumentos en la concentración de PM y las tasas de mortalidad debido a COVID-19 ${ }^{23}$. Diferentes experimentos han tratado de configurar la relación del SARS-COV-2 y la presencia en el aire ${ }^{24}$. La observación de ARN del SARS-CoV-2 en el material obtenido de las partículas en Bérgamo, cerca de Milán y que representa el epicentro de la epidemia italiana, parece confirmar (al menos en el caso de la estabilidad atmosférica y altas concentraciones de PM), que el virus puede crear acumulaciones junto con las partículas y ser transportado y detectado en $\mathrm{PM} 10^{25}$. Aunque no se pueden hacer suposiciones sobre el vínculo entre este primer hallazgo experimental y la progresión o severidad del brote de COVID-19, la presencia de ARN de SARS-CoV-2 en PM10 de muestras de aire exterior en cualquier ciudad del mundo podría representar un indicador temprano potencial de difusión del COVID-19. La búsqueda del genoma viral en partículas puede, por lo tanto, explorarse entre las posibles estrategias para adoptar todas las medidas preventivas necesarias antes de que comiencen las futuras epidemias ${ }^{26}$.

El grado en que el virus COVID-19 induce estrés respiratorio en individuos infectados puede verse afectado por el nivel en que el sistema respiratorio de la persona ya ha estado comprometido. Los altos niveles de contaminación por partículas de polución (PM) en China han podido aumentar la susceptibilidad de la población a síntomas más graves y complicaciones respiratorias. Además, los contaminantes oxidantes en el aire pueden afectar la función inmune y atenuar la eficiencia del pulmón para eliminar el virus en los pulmones. La inhalación simultánea de contaminantes químicos en PM, especialmente las partículas menores a 2,5 ?m, junto con el virus COVID-19, también puede exacerbar el nivel de infección por COVID-1927. La proinflamación, las lesiones y la fibrosis causadas por las PM inhaladas, combinadas con una respuesta inmune o una tormenta de citoquinas inducida por la infección por COVID-19 podrían incrementar la gravedad de la infección. En la medida en que el número de pacientes mostraba síntomas de infección más severa, se originó un mayor riesgo potencial de transmisión ${ }^{28}$.

\section{El riesgo cardiovascular y la infección por COVID-19}

Las características clínicas de la infección por COVID-19 manifiestan una susceptibilidad mayor y un desenlance peor en pacientes con riesgo cardiovascular ${ }^{29}$. Pese a que los estudios requieren datos con mayor grado de evidencia, las personas de edad avanzada con hipertension arterial, diabetes mellitus y obesidad, entre otros, infectadas por COVID-19 tienen más del $80 \%$ de riesgo de fallecer en comparación con personas sin estas comorbilidades ${ }^{30,31}$. La infeccion viral puede ser asintomática o producir síntomas respiratorios leves (tos seca, fiebre, rinorrea, síntomas gastrointestinales) en la mayoría de las personas. Un 14\% tienen síntomas severos con disnea (frecuencia respiratoria > 30/min), saturación de oxígeno $<92 \%$, infiltrados pulmonares) y un $5 \%$ tienen síntomas con falla respiratoria, shock séptico y falla multiórganica $^{12}$. Desde el punto de vista fisiopatológico, durante la unión del virus del receptor ACE2 en presencia de TMPRSS2 (proteína de membrana de la célula humana), el virus puede ingresar a través de la fusión de la membrana o mediante endocitosis. El ARN viral se transcribe luego por el ribosoma de la célula huésped y también se transporta 
al retículo endoplasmático para incrementar la activación transcripcional y la producción de proteínas del componente viral ${ }^{32}$. Este proceso puede destruir la célula huésped y desencadenar una liberación de señales que activan las respuestas inmune innata del huésped ${ }^{33}$. En la infección por SARS-CoV-2 se ha observado una respuesta inflamatoria exagerada caracterizada principalmente por secreción de citocinas proinflamatorias aberrantes, asociada a gran cantidad de macrófagos, con disminución de células T-CD4 ${ }^{+}$ y $\mathrm{T}-\mathrm{CD} 8^{+}$, pero no en células $\mathrm{B}$, con sobreproducción de IL-6, IL-2R, IL-10 y TNF $\alpha$ y disminución de la expresión de IFN $\gamma$, lo cual se correlacionó con la gravedad de la enfermedad y la falla multiorgánica ${ }^{34}$. La inflamación puede tener un efecto local en la microvasculatura donde las células musculares lisas, sometidas a la proliferación viral y al daño celular, liberan citoquinas proinflamatorias que contribuyen a la propagación de lesiones microcirculatorias. El endotelio disfuncional se vuelve proadhesivo y pro-coagulante. Los macrófagos a nivel vascular también pueden liberar factores procoagulantes, como el activador del plasminógeno. Con la alteración de la función de los receptores ACE2 y la activación de angiotensina II, la producción de PAI-I también se incrementa. Esta combinación de eventos acelera aún más la inflamación vascular y empora el estado protrombótico ${ }^{35}$. La presencia de microangiopatía y microtrombos predispone al paciente a microinfartos dentro de múltiples órganos, como el hígado, el corazón o el riñón, lo que exacerba aún más el estado de lesión generalizada y la falla multiorgánica (fig. 2). Estudios preclínicos y clínicos han demostrado que los pacientes hipertensos, en terapia con inhibidores del sistema renina-angiotensina-aldosterona (RAAS), al igual que los pacienes diabéticos, tienen aumento de la expresión de los recepores ACE2 ${ }^{36-38}$.

En conclusión, la enfermedad desencadenada por el SARS-Cov-2 es un gran desafío para las políticas públicas en relación con las estrategias para contrarrestar este tipo de infecciones. Es, por tanto, un reto establecer el vínculo de las enfermedades crónicas no transmisibles y los conocimientos en epidemiología, así como la biología del virus.

\section{Conflicto de intereses}

El autor declara que no hay conflicto de intereses en el presente manuscrito.

\section{Agradecimientos}

A María Grazia Girone y al grupo de Endocrinología Ambiental de la Asociación Colombiana de Endocrinología.

\section{Bibliografía}

1. Corman VMD, Niemeyer D, Drosten C. Hosts and Sources of Endemic Human Coronaviruses. Advances Virus Research. 2018;100:163-88.

2. Walls AC, Park YJ, Tortorici MA, Wall A, MCGuire AT, Veesler D. Structure, function, and antigenicity of the SARS-CoV-2 spike glycoprotein. Cell. 2020;181:281-92, e6.

3. Lan J, Ge J, Yu J, Shan S, Zhou H, Fan S, et al. Structure of the SARS-CoV-2 spike receptor-binding domain bound to the ACE2 receptor. Nature. 2020.
4. Wan Y, Shang J, Graham R, Baric RS, Li F. Receptor recognition by the novel coronavirus from Wuhan: an analysis based on decadelong structural studies of SARS coronavirus. J Virol. 2020;94, pii: e00127-20.

5. Wrapp D, Wang N, Corbett KS, Goldsmith JA, Hsieh CL, Abiona O, et al. Cryo-EM structure of the 2019-nCoV spike in the perfusion conformation. Science. 2020;367:1260-3.

6. Liu PP, Blet A, Smyth D, Li H. The Science Underlying COVID-19: Implications for the Cardiovascular System. Circulation. 2020.

7. Coutard B, Valle C, de Lamballerie X, Canard B, Seidah NG, Decroly E. The spike glycoprotein of the new coronavirus 2019nCoV contains a furin-like cleavage site absent in CoV of the same clade. Antiviral Res. 2020;176:104742.

8. Andersen KG, Rambaut A, Lipkin WI, Holmes EC, Garry RF. The proximal origin of SARS-CoV-2. Nat Med. 2020;26:450-2.

9. Wong MH. 3 billion journeys: World's biggest human migration begins in China. CNN news. 2020;2.

10. Rothan HA, Byrareddy SN. The epidemiology and pathogenesis of coronavirus disease (COVID-19) outbreak. J Autoimmun. 2020;109:102433.

11. Rudan I. A cascade of causes that led to the COVID-19 tragedy in Italy and in other European Union countries. J Glob Health. 2020;10:010335.

12. Wu Z, McGoogan JM. Characteristics of and Important Lessons From the Coronavirus Disease 2019 (COVID-19) Outbreak in China: Summary of a Report of 72314 Cases From the Chinese Center for Disease Control and Prevention. JAMA. 2020.

13. Guan W, Ni Z, Hu Y, Liang WH, Ou C, He J, et al. China Medical Treatment Expert Group for Covid-19 (2020) Clinical Characteristics of Coronavirus Disease 2019 in China. N Eng J Med. 2020;382:1708-20.

14. WHO. Coronavirus disease (COVID-19) Pandemic. New York: WHO; 2020. Disponible en: https://www.who.int/emergencies/diseases/novelcoronavirus-2019/events-as-they-happen.

15. Dean KR, Krauer F, Walloe L, Lingjaerde OC, Bramanti B, Stenseth NC, et al. Human ectoparasites and the spread of plague in Europe during the Second Pandemic. Proc Natl Acad Sci U S A. 2018;115:1304-9.

16. Ho S. OPINION: is there a connection between luxury fashion brands' Dirty Underground Secret And Italy's Coronavirus Crisis? Green Queen. 2020;2.

17. Lopez MM, Holmes SM. Raids on immigrant communities during the pandemic threaten the country's public health. Am J Public Health. 2020:e1-2.

18. Chakraborty I, Maity P. COVID-19 outbreak: Migration, effects on society, global environment and prevention. Sci Total Environ. 2020;728:138882.

19. Bryner J. Why are so many people dying of COVID-19 in New York City? Life Science [Internet]. 2020.

20. Guo ZD, Wang ZY, Zhang SF, Li X, Li L, Li C, et al. Aerosol and surface distribution of severe acute respiratory syndrome coronavirus 2 in Hospital Wards, Wuhan. China, 2020. Emerg Infect Dis. 2020;26.

21. Morawska L, Cao J. Airborne transmission of SARS-CoV-2: The world should face the reality. Environ Int. 2020;139:105730.

22. Haines A, Scheelbeek P. The health case for urgent action on climate change. BMJ. 2020;368, m1103.

23. Exposure to air pollution and COVID-19 mortality in the United States: A nationwide cross-sectional study [Internet]. 2020.

24. van Doremalen N, Bushmaker T, Morris DH, Holbrook MG, Gamble A, Williamson BN, et al. Aerosol and Surface Stability of SARS-CoV-2 as Compared with SARS-CoV-1. N Engl J Med. 2020;382:1564-7.

25. Setti L, Passarini F, De Gennaro G, Barbieri P, Perrone MG, Borelli M, et al. Airborne Transmission Route of COVID-19: Why 2 Meters / 6 Feet of Inter-Personal Distance Could Not Be Enough. Int J Environ Res Public Health. 2020;17. 
26. Setti L, Passarini F, De Gennaro G, Barbieri P, Pallavicini A, Ruscio $M$, et al. Searching for SARS-COV-2 on Particulate Matter: A Possible Early Indicator of COVID-19 Epidemic Recurrence. Int J Environ Res Public Health. 2020;17.

27. Gitkind Al, Levin S, Dohle C, Herbold J, Thomas M, Oh-Park M, et al. Redefining Pathways into Acute Rehabilitation During the COVID-19 Crisis. PM R. 2020.

28. Tian H, Liu Y, Li Y, Wu CH, Chen B, Kraemer MUG, et al. An investigation of transmission control measures during the first 50 days of the COVID-19 epidemic in China. Science. 2020.

29. Guan WJ, Liang WH, Zhao Y, Liang HR, Chen ZS, Li YM, et al. Comorbidity and its impact on 1590 patients with Covid-19 in China: A Nationwide Analysis. Eur Respir J. 2020.

30. Clerkin KJ, Fried JA, Raikhelkar J, Sayer G, Griffin JM, Masoumi A, et al. Coronavirus Disease 2019 (COVID-19) and Cardiovascular Disease. Circulation. 2020.

31. Fang L, Karakiulakis G, Roth M. Are patients with hypertension and diabetes mellitus at increased risk for COVID-19 infection? Lancet Respir Med. 2020;8:e21.
32. Shang J, Ye G, Shi K, Wan Y, Luo C, Aihara H, et al. Structural basis of receptor recognition by SARS-CoV-2. Nature. 2020.

33. Fauci AS, Lane HC, Redfield RR. Covid-19 - Navigating the Uncharted. N Engl J Med. 2020;382:1268-9.

34. Cheng G, Guo W, Cao Y, Huang D, Wnag H, Wang T, et al. Clinical and immunologic features in severe and moderate Coronavirus Disease 2019. J Clin Invest. 2020;130:2620-9.

35. Hunt BJ. Bleeding and coagulopathies in critical care. N Engl J Med. 2014;370:2153.

36. Ishiyama Y, Gallagher PE, Averill DB, Tallant EA, Brosnihan KB, Ferrario $C M$. Upregulation of angiotensin-converting enzyme 2 after myocardial infarction by blockade of angiotensin II receptors. Hypertension. 2004;43:970-6.

37. Burrell LM, Risvanis J, Kubota E, Dean RG, MacDonald PS, Lu $S$, et al. Myocardial infarction increases ACE2 expression in rat and humans. Eur Heart J. 2005;26:369-75, discussion 22-4.

38. Soler MJ, Ye M, Wysocki J, William J, Lloveras J, Batlle D. Localization of ACE2 in the renal vasculature: amplification by angiotensin II type 1 receptor blockade using telmisartan. Am J Physiol Renal Physiol. 2009;296:F398-405. 